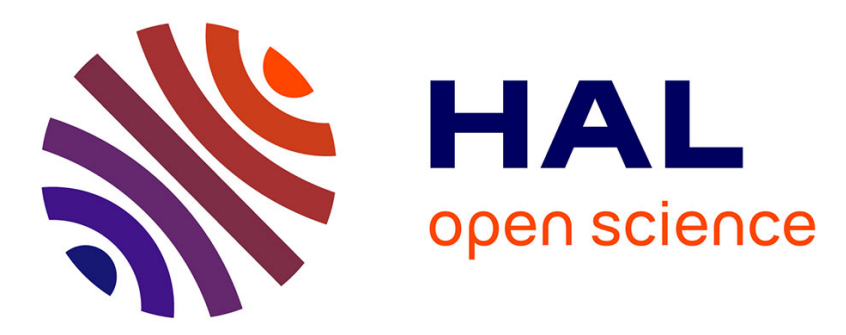

\title{
Working Conditions, Satisfaction of Front-Line Agents and their Intent to quit or stay in French and Japanese Call Centers
}

\author{
Hiroatsu Nohara, Michio Nitta
}

\section{To cite this version:}

Hiroatsu Nohara, Michio Nitta. Working Conditions, Satisfaction of Front-Line Agents and their Intent to quit or stay in French and Japanese Call Centers. Revue de Gestion des Ressources Humaines, 2014, 94 (4), pp.39. 10.3917/grhu.094.0039 . halshs-02924345

HAL Id: halshs-02924345

https://shs.hal.science/halshs-02924345

Submitted on 28 Aug 2020

HAL is a multi-disciplinary open access archive for the deposit and dissemination of scientific research documents, whether they are published or not. The documents may come from teaching and research institutions in France or abroad, or from public or private research centers.
L'archive ouverte pluridisciplinaire HAL, est destinée au dépôt et à la diffusion de documents scientifiques de niveau recherche, publiés ou non, émanant des établissements d'enseignement et de recherche français ou étrangers, des laboratoires publics ou privés. 


\title{
Working Conditions, Satisfaction of Front-Line Agents and their Intent to quit or stay in French and Japanese Call Centers ${ }^{l}$
}

Hiroatsu Nohara,

Chercheur associé au LEST, Aix-Marseille Université, LEST-CNRS

Michio Nitta, Professor Kokushikan University

\author{
PARU DANS: \\ ESKA| « Revue de gestion des ressources humaines "
}

2014/4 No $94 \mid$ pages 39 à 55

ISSN 1163-913X

ISBN 9782747223898

http://www.cairn.info/revue-de-gestion-des-ressources-humaines-2014-4-page-39.htm

Pour citer cet article :

Hiroatsu Nohara et Michio Nitta, "Working Conditions, Satisfaction of Front-Line Agents and their Intent to quit or stay in French and Japanese Call Centers ", Revue de gestion des

ressources humaines 2014/4 ( $\left.N^{\circ} 94\right)$, p. 39-55.

DOI 10.3917/grhu.094.0039

\footnotetext{
${ }^{1}$ We gratefully acknowledge the financial support of the ANR (French research council)-JSPS (Japanese society for promotion of science) joint program for the Research Contract NewDynam 2009-2011.
} 


\section{Introduction}

The development of call centers has accelerated since the mid-1990s in both France and Japan, as well as in the rest of the world. The number of call center agents is now estimated at more than 1 to $3 \%$ of the workforce in most OECD countries (Holman et al., 2007), despite the fact that industrialized countries tend to develop offshore activities, transferring the least complex phone operations to countries with low labor costs.

Call center activity is, in all countries where it is implemented, characterized by a strong prescription of operations and a bureaucratic control through a combination of management and technology. However, this activity typically represents services linked to the management of the “customer relationship". Service quality depends entirely on the ability of the employee to adapt to a wide range of demands from customers and unpredicted events. Therefore, employees face a double constraint: giving satisfaction to the customer through personal commitment, and submitting to rules dictated by the management. This situation in which the agents' personal arbitration is constantly required tends to create a strong nervous tension and mental strain. They themselves often express dissatisfaction and lack of motivation and have withdrawal behaviors or a high rate of turnover. ${ }^{2}$

One of the main issues in call center management is thus to imagine how to reduce these withdrawal behaviors in general and turnover in particular among call center agents: thus the key question is how to make the incentives system better and how to raise the satisfaction level of employees.

This article aims to examine the comparative situation, in France and Japan, of the relationship between working conditions, degree of satisfaction/dissatisfaction and intent to stay or quit on the basis of the voluntary turnover model that Price (2001) has formalized. This model seems to best fit our study in the field of highly constraining workplaces, by placing the cognitive satisfaction of employees at the center of interaction between work environment and mobility choice processes. The France-Japan comparative perspective, based on the assumption of radically different sociocultural contexts, may allow us to bring out not only the regularity of interdependency between society, management and agent, but also the specificity of its societal forms (Maurice, Sellier, Silvestre, 1986).

\footnotetext{
${ }^{2}$ A report (The Global Call Center Report, Cornell University) shows that the annual turnover rate varies from $10 \%$ to $25 \%$ depending on the country. If limited to outsourcers, this figure is at an average of $20 \%$ per year. http://www.ilr.cornell.edu/globalcallcenter/upload/GCC-Intl-Rept-US-Version.pdf
} 
This article starts by reviewing past research on the concept of satisfaction at work and its relationship with turnover intent studies. We will then construct some hypotheses to be tested, taking into account the real working conditions in call centers. The third part will be devoted to the measurement issues, the methodology and the presentation of data. In the fourth part, we will test these hypotheses and report our main results. The text concludes with a synthesis of our results.

\section{I - Literature review}

We already have an enormous literature on the models of interaction between employees' voluntary turnover, their working conditions and/or their job satisfaction. According to Spector, quoted by Lambert et al. (2001), by the mid-1990s, there were more than 12,000 studies dealing more or less with these themes. This literature is based on carefully prepared tests that are often aimed at a certain number of targeted occupational groups such as nurses, teachers or social workers, etc. Because these interactions were based on very complex procedures within a psycho-organizational "black box", the theoretical models as well as methodological questions -such as the choice of indicators, measurement procedures, the meaning of causality- were subject to contradictory debates among behavioral science researchers. This article does not aim at doing yet another test case related to applied psychology. Based on the "matched" questionnaire, the present study focuses on the concrete analysis of call center agents' attitudes concerning their working conditions and attempts to link these attitudes -satisfaction- to their career prospects within two radically different societal contexts. We will briefly carry out a literature review regarding both the job satisfaction concept and the term "intent to quit or stay", our main variables to be explained.

As far as the first concept is concerned, job satisfaction is, according to many authors (Hom \& Griffeth, 1995; Spector, 1997) one of the most utilized concepts in the field of industrial psychology. It is considered one of the likely mediators linking individuals' behaviors within the organization to their working conditions, which makes it a basic concept in HRM research. Despite the existence of trends that sometimes compete with one another, Locke's divergence theory came up as the main theoretical basis on which job satisfaction can be conceptualized. According to this interpretative position, satisfaction results from the matching between the different facets of work, and the beliefs, expectations and needs towards work that individuals carry. Locke (1976) defines job satisfaction as follows: "a pleasurable or positive emotional state resulting from the appraisal of one's job or job experiences". Thus, satisfaction is related to the subjective stance that the employees will take on their own experience and/or objective environment, meaning their working conditions. In a similar way, Spector (1997) defines job satisfaction as being "simply how people feel about their jobs and different aspects of their jobs. It is the extent to which people like or dislike their jobs". 
However, it is important to make a distinction between satisfaction as an attitude and satisfaction as an emotional state (Weiss et al., 1996; Mignonac, 2004). The emotional state refers to emotions felt during work, while attitude refers to the evaluation of work analyzed through the lenses of contribution/compensation (Roussel, 1996; Weiss, 2002). Job satisfaction is supposed to imply the evaluation, the emotional and/or cognitive judgment that an individual will have on his own working conditions and on the work itself. In other words, we presume that an employee constantly assesses a level of convergence between what he/she wants and what he/she gets from the different aspects of work. In this study, the emphasis will be put on such attitudinal dimensions of job satisfaction. Moreover, we keep in mind that satisfaction is not an immutable concept, but a dynamic perception which can evolve in the life course, according to the experiences and expectations of the individual (Igalens, 1999). As a result, we need to take seriously the socio-demographic factors in our analysis.

As regards the intent to quit, this refers to the employee's conscious desire to terminate the employment contract with his/her company. Some authors use different formulae which translate the same idea, such as the voluntary intent to quit, turnover intent, intention to leave or, on the contrary, intent to stay. The latter can be defined as "the employee's aspiration to remain a member of the organization" (Mueller et al., 1992). A majority of authors use the terms "intent to quit or to stay", and define them as "a likely mediator to the attitude-behavior relationship [which] represents the last step prior to quitting or remaining" (Zimmerman \& Darnold, 2009). Thus, they clearly locate the intent to quit/stay within a process; the intent to quit/stay would thus act as a predictor of the employee's decision to leave or to stay.

Voluntary turnover models have long tried to assess the job satisfaction of employees and their perception of the quality of their engagement with their companies (Price, 1977, 2001; Mobley, 1982; Lambert et al., 2001). Voluntary turnover, meaning turnover freely initiated by the employees, is defined as "the voluntary departure of existing employees from the organization" (Price, 2001). This act is commonly viewed one of the major negative reflections of attitudes at work, such as job dissatisfaction, frustration, non-commitment or distrust towards the company (Mathieu \& Zajac, 1990; Meyer et al., 2002). Serious dissatisfactions can strongly damage the "psychological contract" based on the mutual engagement between employee and his/her company (Rousseau, 1995) and the definitive break-up is very often the only way out in such case. Freeman and Medoff (1984), based on the famous formula "Exit, Voice and Loyalty" of Hirshman (1970), suggest in their model that the alternative choices of the employee with job dissatisfaction would consist in exiting the company, or voicing it out through the collective actions such as claims, protests or even strikes, etc. Given satisfactory working conditions, the employee would on the contrary be interested in keeping a sustainable tie with his/her employer. This can in turn strengthen the organizational commitment of 
the employee. The turnover model proposed by Hom and Griffeth (1995) aims at exploring the cognitive steps prior to exit, based on satisfaction and organizational commitment. On the basis of the referent cognitions theory, this model posits that the satisfaction of the employee is linked to his/her perception of justice related to the convergence/divergence between procedures and outcomes within his/her company or compared to other companies. Thus, the more an individual perceives an injustice, the more he/she will be dissatisfied and the more likely he/she is to enter a process of withdrawal cognitions which could lead to a voluntary exit at the end. However, this model seems to fail to elucidate the role of the organization and its practices in this process.

Compared to previous models, the voluntary turnover model proposed by Price (2001) includes a wide range of organizational practices and, through this, refines the linkages between working conditions, job satisfaction and the intent to quit. Since a job represents an interconnection of tasks, roles, responsibilities and at the same time an interaction between motivations and rewards, a deepened understanding of attitudes at work seems to require that the job be analyzed through a whole set of factors that constitute it. Price's causal model is built on the synthesis of three approaches: the basic expectancy approach, the social exchange approach and the cost-benefit approach. His model encompasses three major categories of variables: 1) the determinants of the external environment (opportunity and kinship responsibility); 2) individual determinants (general training, job involvement, positive/negative affectivity); 3) the determinants of the internal environment (job stress, pay, autonomy, distributive justice, promotion, "routinization" and social support). In this model, all the determinants of the internal environment, linked both to job satisfaction and to organizational commitment, correspond to diverse facets of HRM practices.

Aside from Price's works, numerous other empirical studies have been done on the correlation between job satisfaction and the intent to quit, as shown by several meta-analyses (Tett and Meyer, 1993; Meyer et al., 2002). They highlight the fact that it is very often a direct and negative link (Steel \& Ovalle 1984; Hellman 1997). However, some have found that this link is merely indirect, mediated by the organizational commitment (Lambert et al., 2001). Price (2001) explains that each of the variables contributes independently to the turnover process, and that, while correlated, job satisfaction and organizational commitment are distinct constructions. Clugston (2000) and Tett \& Meyer (1993) come to a similar conclusion and add that intents or behaviors are more realistically predicted by job satisfaction than organizational commitment. 


\section{II - Choice of model and construction of hypotheses}

Price's explanatory model seems to be best suited to our field of investigation, the call center sector. However, we bring some modifications through simplification. First, we only take into account the variables related to the internal environment, since our focus is on the links between organizational practices and employee satisfaction. Second, we only consider the causal channel "Working conditions -> Satisfaction $\rightarrow>$ Intent to quit/stay", leaving aside the other channel which runs through organizational commitment. Given the nature of the work in call centers, satisfaction appears to be a potential mediator that is more immediately linked to the cognitive process leading to departures.

In our studies, we try to apply the Price model in two sequential steps: first we measure the impact of factors such as employment conditions (nature and length of the contract), the rewards structure (pay and bonus, etc.) and working conditions per se (working hours, autonomy, etc.) on the satisfaction of agents. Then we examine the influence of job satisfaction on the intent to quit or stay.

Often regarded as a "tertiary factory", call centers are thought of as a typical Taylorian model applied to services. This activity is characterized by a strong prescription of operations and bureaucratic control: the productivity gain objectives are fixed by the management and are controlled by efficient software programs. The phone conversation is largely standardized by scripts. The combination of phone with computer technologies imposes a pace to follow, automatically switching phone calls towards non-occupied posts. For example, Taylor and Brain, based on an analysis of the labor process in British call centers, use the image of an "assembly line in the head" leading to various forms of individual or collective resistance (Taylor \& Bain, 1999; Russel 2002).

However, the production of front-line services also has its own characteristics that differentiate it from industry. In contrast to factory work, call center activities are based on a provision of direct services linked to the immediate treatment of the "customer relationship". Due to their relational content, these services can hardly be standardized and thus are difficult to predict a priori (Frenkel et al., 1999). A good quality service can only be obtained through personalized answers to customers bringing various and heterogeneous demands. During their phone operations, call center agents thus have to add an extra "commercial" value, using their emotional and social skills and adapting to unpredicted events. The service quality, measured by customer satisfaction, depends on their attitudes alone, which become strategic in order to ensure the loyalty of the customer (Clergeau 2004). 
Ultimately, agents must face the ambiguity of the productive objectives of call centers and the tensions existing between logistic criteria and good service quality criteria: the rationalization of activities by the computer system is very strong and the hierarchy exerts a close surveillance, whereas the quality of the service depends only on the behavior of agents facing the customer. Such a tense situation generates a lot of stress, and sometimes creates a very difficult working environment. As a result, it may reinforce emotional exhaustion, strong withdrawal behavior (absenteeism, sickness leave) and a high level of quit rate. By contrast, if one can give them more room for maneuver on such things as the working pace, or the opportunity to make their own answers, one could gain better efficiency results, and especially a greater satisfaction at work which would in turn lead to a decrease in the voluntary turnover rate. Similarly, as the phone operations become repetitive in the long run, blocking the job "routinization" could attenuate the feeling of monotony and fatigue. According to our field survey, the job complexity factor acts in the same way as job autonomy: adding sales action or claim handling to basic call operations reinforces both the skill of call center agents and their motivation.

These characteristics bring to us three initial hypotheses to be tested:

Hypothesis I: The degree of satisfaction increases as the perceived stress becomes weaker.

Hypothesis II: The degree of satisfaction improves as the occupational autonomy of employees increases.

Hypothesis III: The degree of satisfaction improves as the job contents become more complex.

Many authors explicitly adopt the social exchange theory which distinguishes the two types of exchange. They make a distinction between transactional contracts based on socio-economic exchanges and relational contracts orientated towards psychological exchanges. While the former must fulfill their mandatory reciprocal efforts/monetary transactions, the latter must meet the commitment/psychological rewards obligation. The psycho-sociological approach places analytical primacy on the influence of relational contracts impacting the intrinsic motivation (Deci \& Ryan 1985) of employees, such as trust, loyalty, and organizational commitment (Allen \& Meyer 1997). In parallel, they neutralize or very often undervalue extrinsic motivation factors linked to transactional contracts, especially monetary compensations. Even though factors linked to intrinsic motivation are important -in certain occupations, such as nurse or teacher- wage is a core factor of the wage-labor nexus that cannot be ignored in order to understand the (dis)satisfaction and implication/withdrawal behaviors of employees. This is true in particular when it comes to employment in call center activity, which is often regarded as a simple "instrumental" job. We will thus test this second group of hypotheses. 
Hypothesis IV1: Higher pay level improves the degree of satisfaction.

Hypothesis IV2: Bonuses - with a collective dimension-increase the degree of satisfaction.

Hypothesis IV3: Performance-related pay as an individual form of distributive justice increases the degree of satisfaction.

Other elements of the hypothesis relate to, on one hand, the use of working time and on the other hand, employment conditions (nature of the contract, duration of seniority, etc.). All factors reinforcing the commitment of employees within the organization could be generally considered as increasing the level of satisfaction. For example, this is the case with open-ended contracts over other forms of temporary contracts, or full-time jobs compared to part-time jobs. Equally, senior employees tend to feel more committed to the organization compared to newcomers who are trying to adjust their level of effort to the level of compensation (Lambert et al. 2001). Regarding this, we put forward a last set of four hypotheses:

Hypothesis V1: Open-ended contracts procure a greater degree of satisfaction than time-fixed contracts or temp contracts.

Hypothesis V2: Longer seniority is related to more satisfaction.

Hypothesis V3: Full-time work procures a greater degree of satisfaction than part-time work.

Hypothesis V4: Longer working time generates more satisfaction.

After these hypotheses concerning the first step, we attempt to explore the relationship between satisfaction/dissatisfaction and the intent to quit/stay in the second step. We also test the moderating effects of labor institutions on satisfaction on the basis of Freeman \& Medoff's thesis.

Hypothesis VI1: Greater degree of satisfaction increases the intent to stay and diminishes the intent to quit.

Hypothesis VI2: Labor organizations such as unions or employee representatives diminish the intent to quit, as their collective voicing function weakens dissatisfaction.

\section{III - Survey population, Measurement and Methodology}

After presenting the nature of our data, the characteristics of the survey population, we will quickly address the problems concerning the measurement of concepts such as satisfaction, autonomy and stress, and methodology issues. 
Box: A presentation of the call center surveys in France and Japan

This research was carried out in 2010-2011, by the LEST and the Institute of Social Science (University of Tokyo) teams on a common methodological basis: the same questionnaire (50 items) was translated into each language and implemented. We obtained 831 responses in France (351 through the Internet and 480 questionnaires distributed to 12 establishments), whereas in Japan, we got 450 answers back through the Internet, and 570 answers from 8 establishments to which the questionnaires were directly addressed. The French sample is overrepresented by the telecom sector and outsourcers, and the Japanese sample by the banking and insurance sectors. Despite these biases, we could not carry out a sample correction, because of a lack of official statistics on this sector; our samples may not be therefore nationally representative, although reflecting the population of large call centers.

The survey population is exclusively made up of employees working in front offices. After excluding the first-level supervisors and the unanswered questionnaires, we were left with sample of 721 agents in Japan and 613 in France.

Call center agents are mostly female in both countries. Women represent $71 \%$ of the sample in France and $81 \%$ in Japan. This reflects one of the characteristics of this activity, a symbol of a service economy offering numerous job opportunities to women. But their marital situation seems to be slightly different in the two countries: in France, the majority (61\%) live with a partner, against only $46 \%$ in Japan. They are also younger in France: the average age is 32, as against 39 in Japan. While French agents are thus overall younger, their Japanese counterparts fall into two categories: single young women, and older married women. As for their qualification, most of them graduated from high school in both countries. 42\% in France and 47\% in Japan hold a tertiary education level degree. This high qualification level is consistent with other statistical sources (Holman et al., 2007).

As regards employment conditions, many differences can be observed - except for senioritywhich reflect institutional settings. First, median seniority is 2 years in France, and 3 years in Japan. The number of those with more than 8 years of seniority is limited both in France (14\%) and in Japan $(12 \%)$. In both countries, the average seniority is rather short, which corroborates the high quit rate.

The two countries have built their labor standards on very distinct historical bases; the nature of the contract is thus heterogeneous (Nohara, 1999). In France, the open-ended contract is the norm, whatever the field or the job. The time-limited contract only represents a small population: respectively $5 \%$ for temporary contracts and $13 \%$ for fixed-term contracts. Furthermore, part-time workers are also a very small minority (6.5\%), even if these jobs are mostly "female jobs" such as supermarket cashier. Japan's situation is radically different. Only $11.5 \%$ are on open-ended contracts with a "permanent status". On the other hand, $23.5 \%$ work with a fixed-term contract and $65 \%$ with a "temp contract". This last status does not really correspond to the notion of "temp work", as it usually implies a particular form of outsourcing. In the banking or insurance sector where very 
confidential financial information is dealt with, classic long distance outsourcing is forbidden. Japanese banks and insurance companies have chosen to create for themselves, within their own offices, a call center whose human resources are managed by outsourcers-subcontractors. Consequently, the outsourcers, and not the temp worker companies, supply their own employees, managers included. Most of the employees nevertheless have a fixed-term contract.

As to the working regime, French employees habitually work with a "normalized" weekly working time - 35 hours per week. In fact, $71 \%$ of employees are on open-ended contracts and work an average of 35/36 hours per week. Japanese employees, and particularly women, show different and varied working regimes: those who work less than 15 hours per week represent $20 \%$ and those working between 15 to 34 hours per week 40\%. The remaining (40\%) work more than 35 hours, most of them working between 40 and 45 hours per week.

Pay issues are one of the most sensitive aspects of employment contracts in both countries. The wage difference in France is minimal, as the range between the $1^{\text {st }}$ quartile ( 8.9 euros) and the 3rd quartile (10.3 euros) is only 1.4 euros compared to the median wage of 9.3 euros. The wage range in France appears to be particularly compact. On the other hand, the hourly wage of Japanese workers ranges from 9.8 euros (1st quartile) to 15.7 euros (3rd quartile) with a median wage of 13.7 euros. In Japan, wages can be very different depending on the nature of the contract, seniority, qualification, etc. The wage variable is the hourly wage transformed into a natural logarithm. Performance-based pay is an individual reward, while bonuses are rather collective. Union membership concerns $16 \%$ of employees in France and only 5\% in Japan, while $84 \%$ of agents are covered by the workers' representative systems in France and 31\% in Japan.

In order to measure our main variables of interest, we created a series of composite indicators.

First of all, the measurement of our dependent variable, which is the degree of perceived satisfaction, has been done with principal components analysis with four facets of satisfaction (Annex A). We used the first of four components, which explains $63 \%$ of the total variance in France (Cronbach $\alpha=0.80$ ) and $68 \%$ in Japan (Cronbach $\alpha=0.84$ ), to turn it into the satisfaction score. Here the higher the score, the greater the degree of satisfaction perceived by agents.

We built also two indicators of autonomy and stress, measured with self-declaratory answers. More or less biased as it is, it still allows assessment by the employees on their perception of their own working conditions in call centers. The indicator of "autonomy" is composed of two variables: the use of scripts (on a scale of 1 to 3 ) and the amplitude of the control over the working pace (Likert scale from 1 to 5). They indicate the call center agents' scope for autonomy in their work. After 
having standardized them, we created the measurement score by addition. The higher the score, the more autonomy the employee has.

To measure stress, we selected five items used in the GHQ-12 (general health questionnaire). The stress indicator was based upon the method of principal components analysis from a series of five questions modified to fit the call center sector (Annex B). We kept the first of four components, which explains $57 \%$ of the total variance in Japan (Cronbach $\alpha=0.86$ ) and $56 \%$ in France (Cronbach $\alpha=0.80$ ), to turn it into the stress score. Here again, the higher the score, the more stressful feeling the employee perceives.

We adopted an approach which consists in testing separately the relationship between satisfaction and organizational practices, and the relationship between satisfaction and intent to stay or quit. Satisfaction is here expected as a mediator variable. We used the OLS regression model for the first step and the multinomial probit model for the second step. In each model, the control variables are introduced: socio-demographic characteristics like age, sex and marital status in the first OLS model; in the second model, we brought together the companies' statuses (in-house call centers or outsourcers) and the five sectors (bank, insurance, industry, commerce, telecommunications). Moreover, we added the variable of union membership (unionized or not) and another variable related to the presence or not of a labor representative (délégué du personnel).

\section{IV-Results in the first step (Job satisfaction model) and the second step (multinomial probit model) and discussion}

Table 1: Job satisfaction OLS regression model

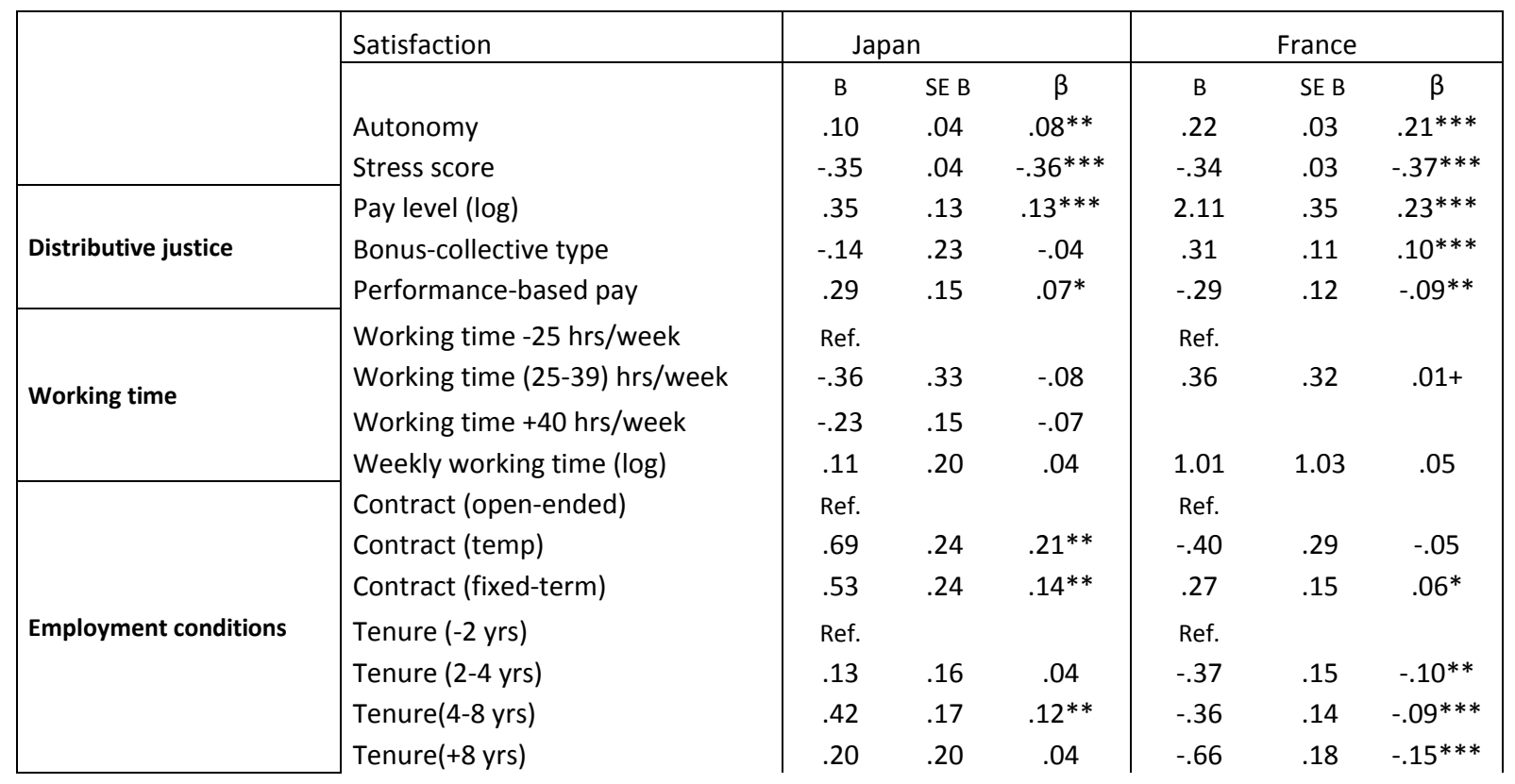




\begin{tabular}{|c|c|c|c|c|c|c|c|}
\hline \multirow{2}{*}{ Routinization } & Sales action & -.53 & .17 & $-.13^{* * *}$ & .28 & .11 & $.09 * * *$ \\
\hline & Claim handling & -.32 & .13 & $-.07 * *$ & -.09 & .10 & -.02 \\
\hline \multirow{9}{*}{$\begin{array}{l}\text { Socio-demographic } \\
\text { characteristics }\end{array}$} & age & -.13 & .04 & $-.81^{* * *}$ & -.04 & .04 & -.23 \\
\hline & age2 & .001 & .0005 & .66 & .0005 & .0005 & .22 \\
\hline & Single man & Ref. & & & Ref. & & \\
\hline & Married man & .12 & .27 & .03 & -.16 & .19 & -.04 \\
\hline & Single woman & .32 & .17 & $.09+$ & .12 & .17 & .03 \\
\hline & Married woman & .86 & .19 & $.24^{* * *}$ & -.01 & .16 & -.004 \\
\hline & Diploma (high school cert. or less) & Ref. & & & Ref. & & \\
\hline & Diploma (high school cert.+2 yrs) & -.09 & .12 & -.03 & -.07 & .10 & -.02 \\
\hline & Diploma (high school cert.+4 yrs) & -.50 & .18 & $-.12 * * *$ & -.90 & .18 & $-.15^{* * *}$ \\
\hline & Constant & 1.23 & 1.24 & -.006 & $-7.16+$ & 3.75 & .001 \\
\hline & Number of observations & \multicolumn{2}{|c|}{721} & & \multicolumn{3}{|c|}{613} \\
\hline & $F(22,698) \quad F(21,592)$ & \multicolumn{2}{|c|}{10.46} & & \multicolumn{3}{|c|}{27.75} \\
\hline & R-squared & \multicolumn{2}{|c|}{0.2563} & & \multicolumn{3}{|c|}{0.4751} \\
\hline & Root MSD & \multicolumn{2}{|c|}{1.458} & & \multicolumn{3}{|c|}{1.1556} \\
\hline
\end{tabular}

Note 1: B represents the unstandardized coefficients, $\beta$ the standardized coefficients. Note $2:{ }^{* * *}$ Statistically significant at the .001 level; **at the .01 level;* at the .05 level; + at the .10

\section{IV-1 First step: determinants of job satisfaction model}

Table I shows the first results of the OLS regression models designed to examine which factors are associated with the degree of satisfaction ${ }^{3}$. This model fits the French case better than the Japanese one: this model explains $48 \%$ of variance in France, but only $26 \%$ in Japan. The socio-demographic factors -control variables- only explain a small part of the model (3\% in France and 6\% in Japan), while the rest is determined by job-related variables.

From an overall point of view, we can note the coexistence of two types of logic: each population comes across with general variables acting in similar manners in both countries, and more specific variables due to the national context within which they are framed ${ }^{4}$.

As noted above, the working environment of call center activity is characterized by the importance of measurement of the agents' work, reducing their margin of autonomy. Moreover, because the volume of work in call center activity fluctuates widely, employees are subjected to this rhythm imposed by the market. This leads to the adoption of more modern forms of work rationalization, based in particular on the just-in-time principle. This situation, along with the nature of emotional labor, tends to generate high nervous tension, mental stress or emotional burnout (Zepf, 2002).

\footnotetext{
${ }^{3}$ We also tested the ordered logit regression model with the "overall satisfaction statement" and obtained a very similar result, which confirms the robustness of our estimation.

${ }^{4}$ Sectoral composition effects -variation of sectors in the two countries- are here controlled.
} 
Indisputably, the following two variables -which mutually interfere- appear as essential to understand the satisfaction levels in both countries: stress and autonomy. As expected, our hypotheses I and II are strongly supported by the high statistical significance that these two variables show.

The indicator of stress is negatively -and powerfully- correlated with the degree of satisfaction both in Japan and in France. This means that satisfaction increases significantly as the working environment is less and less stressful. We note that the impact of the perceived stress is as strong in Japan as in France, although their working environments such as working time or pace, call number by day, etc. are slightly different in the two countries.

The relationship between stress, satisfaction and occupational autonomy is based on a very old debate amongst industrial psychologists. According to an interactional approach developed by Lazarus and Folkman (1984), “stress appears when there is an imbalance between a person's perception of the constraints imposed by his environment and his perception of his own resources to cope with them." The degree of stress therefore rises if the employee feels inadequately equipped to face a situation, because he/she does not have the resources to respond to the constraints of the environment. Karasek (1979) also emphasizes the "decision latitude" the employee has in dealing with the demands and expectations of the work to be done. In the case of call centers, autonomy is measured by the degree of control over the rhythm of work and the latitude allowed on the use of the script. Our result is thus entirely in line with what these theories predict. Call center agents perceive less stress and more satisfaction if they have more autonomy when performing their work (Nohara \& Tchobanian, 2014).

One another variable which has a robust effect in both countries is pay. Pay level is significantly correlated with the degree of satisfaction; the higher the pay level is, the stronger the satisfaction the employee perceives. This correlation is a common ground to both countries, even if it is slightly stronger in France than in Japan. Hypothesis IV1 is largely confirmed.

Numerous studies have already highlighted the importance of the pay level, as the employee perceives his own situation by comparing and forges his own opinion referring to criteria he himself sets (Neveu 1996; Lum et al.,1998). This notion of relative pay reveals the match between effort and wage level. As expressed by the wage efficiency theory formula (Akerlof 1982), a high wage level acts as an incentive. If this match is not established, or set under a minimal level, the individual tends to feel a certain frustration and readjusts - often downwardly- his own level of effort to the wage level. Our test reveals that pay level per se plays a significant role in the determination of satisfaction. 
The three variables mentioned above are basic ones and both in Japan and in France underpin the common structure of call center activities in general and their human resources management in particular. Besides these variables, it is possible to observe specific variables or context-dependent variables which exercise an impact only on the French context or on the Japanese one. These variables may reflect some organizational or even national features of human actions. Generally, Japanese agents differentiate themselves by their individual characteristics -age, gender, marital status, diploma- when it comes to the degree of satisfaction, whereas their French counterparts are more divided according to their working conditions.

As to the groups of employment conditions-related variables, we note several statistical results which go against our expected outcomes.

The variables concerning the working time regime have no significant effect on the degree of satisfaction in the two countries. So hypotheses V3 and V4 are rejected. As for the nature of the employment contract, the results are counter-intuitive, because call center agents having fixed-term contracts in the two countries and even those who work with temp contracts in Japan show a greater degree of satisfaction than agents with open-ended contracts. Hypothesis V1 is therefore rejected. For now, we cannot find any robust explanatory elements, but one of them may lie in the labor intensity difference between the two categories of employees: permanent status employees may have very high labor intensity, including longer working time and the need to do shift work, whereas non-regular status employees can limit their physical (working pace, fixed working hours, etc.) and psychical commitments at work. These differences can create different subjective perceptions of the effort/compensation ratio, which can lead to a negative feeling of satisfaction among employees with open-ended contracts. The duration of seniority has contrasting effects on satisfaction: while this factor works rather positively -but not always statistically significantly- upon the increase of satisfaction in Japan, the same factor works negatively in France. In the latter case, call center agents become more and more dissatisfied as they accumulate experience in call centers. This implies that French agents feel a certain fatigue along the time/experience path and become progressively frustrated. Our field survey revealed that French agents often complain about wage stagnation at the earlier stage of their career, as they have very few pay ladders (only two ladders in the collective agreement of Syntec service sectors). Mental exhaustion and slow pay progression in call centers are thus very likely to produce a sense of dissatisfaction, especially among senior employees. This is all the more interesting in that this trend goes against the side-bet theory of Becker (1961), according to which tenure tends to increase the emotional commitment of employees in the organization and to strengthen the degree of satisfaction and loyalty. In Japan, this variable has no strong significant impacts, but works in accordance with the theoretical prediction. Hypothesis V2 is confirmed in Japan 
but refuted in France. To continue with the incentive mechanism, we examine hypotheses II2 and II3 which are concerned with the form of distributive justice. Bonuses significantly increase satisfaction in the French case, but not in the case of Japan. By contrast, performance-related pay, much valued in Japan, increases the satisfaction of Japanese employees, while this form of pay is negatively correlated with satisfaction in France. This means that the Japanese employees have more "individualistic" behavior than their -more collective- French counterparts, who do not appreciate the measurement of individual performance. As noted above, the wage dispersion in France is flatter and much more compressed, compared with the Japanese one. This contrast, counter-intuitive to a general culturist view, demonstrates the different nature of pay justice embedded in the social contexts.

The concept of "routinization" proposed by Price aims at assessing the extent to which jobs are repetitive. Here we measure rather "de-routinization" of call operations often considered as extremely repetitive, by using two - dichotomized- variables: sales actions included in the task duty or not, and claim handling or not. In general, call center activity generates two types of job complexity (Batt et al., 2010). The level of complexity of agent-customer transactions is often inherent in the services themselves. For example, credit card activation or telephone operator services are simple transactions that offer few opportunities for greater complexity. Some high-value services in financial sectors are more likely to demand customized services involving negotiation or construction of novel arrangements. The fact that the agents' task includes or not sales transaction or claim handling is strongly related to the level of job complexity. Hypothesis III is thus confirmed in France as far as sales activity is concerned, but largely rejected in Japan. This means that French employees are rather satisfied with more complex job tasks, whereas the Japanese employees do not appreciate job contents such as sales or claim handling. In the Japanese call centers, managers tend to separate tasks into different job grades, with a high ranking job designed for the permanent workers and many low ranking jobs destined for numerous part-time female workers with low general skills in cross-selling and customer negotiations. Job fragmentation of this kind ${ }^{5}$ seem to allow call centers to hire workers with few responsibilities, without worrying about their motivation.

Last but not least, we incorporated socio-demographic factors into the model as control variables. These factors have no interference in France, except the level of qualification superior to four years of tertiary education. Those who have higher diplomas are not satisfied with call center jobs, compared to less educated employees. Such a situation is common in Japan. This means a sort of over-qualification with regard to the average post offered in the sector. Contrary to the French case,

\footnotetext{
${ }^{5}$ In France, this type of job fragmentation exists between France-based call centers and off-shore call centers (nearly $15 \%$ of call center workers in 2010, according to the CESMO survey), while off-shoring is very limited in Japan where labor flexibility has to be constructed on a national base.
} 
the socio-demographic features of agents in Japan affect their satisfaction. The age variable is positively correlated with satisfaction: seniors are more satisfied than young workers. We combined gender and marital status, creating four categories: single men, married men, single women and married women. Compared with single men, married men show no difference, whereas women are more satisfied. In particular, married women seem to be the most satisfied with this type of jobs. By contrast, men with a permanent contract express much more dissatisfaction, because they serve as a buffer against time and organizational pressures and face more stressful working environments ${ }^{6}$.

While individual variables have little impact whatsoever in France, women and especially married women are significantly less dissatisfied in Japan. In other words, Japanese women often working on fixed-term or part-time contracts have greater job satisfaction than men on open-ended contracts. This implies a kind of segmentation of socio-occupational spaces according to variables such as age, gender, diploma or marital status, etc. which are strongly associated with the diversified expectations and attitude of employees in Japan, whereas the same socio-occupational space is more homogenous in France, except for highly educated people. This matches one of our findings: the management style is very different in the call center sectors of the two countries, particularly concerning HRM, which is fine-tuned in Japan to adapt its policies to a variety of employees having a large range of expectations, while French HRM appears more "monolithic" in its policies and regulated heavily by the "egalitarian" social norms and the French labor laws.

\section{IV-2 Second step: relationship between satisfaction and intent to quit or stay}

We now examine the second relationship between satisfaction and mobility choice of call center agents. The intention of employees is one of the indicators that allow us to analyze the implicit attitude of the agent within the mutual commitment implied in the employment contract (Rousseau 1995). The construction of synthetic indicators on this matter is usually done through several items, as in the "Michigan Organizational Assessment questionnaire". These Likert-type items are then processed, aggregated and turned into an indicator to be explained. In the end, the latter is integrated into a linear model of regression. Our approach is slightly different: we decided to put this question in a direct and one-choice manner in the questionnaire. The respondents could choose between three alternatives:

1) Wish to stay within the current call center

2) Wish to leave the call center in future

\footnotetext{
${ }^{6}$ While mean stress scores are not significantly different in France by gender or status, this indicator shows 0.44 for men with a permanent status, against -0.10 for single women and -0.26 for the married women in Japan, which means a strong deterioration of perceived stress for the core male workers.
} 
3) Wish to leave the call center rapidly

These choices reflect, at instant $t$, the projection that the employees make of their occupational career in the future. We give an interpretation to each alternative in the following way:

Alternative 1) would correspond to an expression of loyalty to the organization. It is synonymous with the willingness to continue the career within the present call center with a certain degree of personal commitment. This concerns respectively $42 \%$ of agents in France and $46 \%$ in Japan.

Alternative 2) shows an ambivalent behavior which is balanced between a feeling of diffuse discordance, a relative withdrawal cognition and uncertainty about the future. Combined with good external opportunities, this "waiting" behavior could lead to a stronger intent to quit. Those who chose this item represent $40 \%$ of the sample in France and 45\% in Japan.

Alternative 3) would correspond to what is referred to as a "voluntary turnover intent". Even if the intention and the action itself must be considered as two distinct measures, a number of studies show a strong causality between these two measures. Griffeth \& Hom (2000) showed that the variable "declared intent to leave" is, among 35 different variables, the one most strongly correlated with effective departure. $18 \%$ of French agents are willing to move out rapidly, while this is the case with $9 \%$ of Japanese agents.

In order to examine the hypothesis of "voice or exit", the multinomial probit model includes the indicator of satisfaction used above, and two variables associated with union membership and the workers' representative system as moderators. Two control variables (sector, and outsourcing or not) are added. However, we do not have variables associated with external opportunities (external labor market conditions ${ }^{7}$, etc.), which often serve as attraction forces to external mobility. Our focus is then only on the internal conditions of organization mediated by the satisfaction indicator without taking into account the cost/advantage calculation. As for the variable to be explained, the base reference in this model is those who have an ambiguous stance, that is those who "wish to leave the call center in future". We measure the effects of different explanatory variables on those who wish to leave and those who wish to stay, compared with the former.

As shown in Table II, the indicator of satisfaction plays an essential role in the determination of career expectation. In both Japan and France, the satisfaction score is strongly correlated with the career choices: all coefficients are statistically significant under the $0.1 \%$ level. Positively correlated,

\footnotetext{
${ }^{7}$ Note that our surveys were implemented during the period 2010-2011, just after the burst of financial crisis.
} 
greater satisfaction increases the intent to stay, while weak satisfaction reinforces the intent to quit. More precisely, an improvement of one point on the satisfaction scale contributes, by $10 \%$ in France and by $4.6 \%$ in Japan, to the decrease of turnover intent, while it increases the intent to stay by $20 \%$ in France and by $15 \%$ in Japan. The sensitivity of this variable thus appears much stronger in France than in Japan. As a result, hypothesis VI1 is confirmed.

Table II - Multinomial probit model on the career plan choice (intent to quit or stay)

\begin{tabular}{|c|c|c|c|c|c|c|c|c|}
\hline \multirow[b]{4}{*}{ Satisfaction } & \multicolumn{4}{|c|}{ Japan } & \multicolumn{4}{|c|}{ France } \\
\hline & \multicolumn{2}{|c|}{ Stay } & \multicolumn{2}{|c|}{ Quit } & \multicolumn{2}{|l|}{ Stay } & \multicolumn{2}{|c|}{ Quit } \\
\hline & Coef. B & $d y / d x$ & Coef. B & $d y / d x$ & Coef. B & $d y / d x$ & Coef. B & $d y / d x$ \\
\hline & $.469 * * *$ & $.149 * * *$ & $-.204 * * *$ & $-.047 * * *$ & $.568 * * *$ & $.197^{* * *}$ & $-.389 * * *$ & $-.102 * * *$ \\
\hline Union membership & .387 & .090 & .458 & .029 & -.153 & -.272 & -.353 & -.002 \\
\hline Worker Rep. & -.130 & -.039 & .018 & .009 & -.310 & .138 & .537 & .910 \\
\hline Union memb. *sat. & -.136 & -.043 & .055 & .013 & -.022 & .002 & $-.112+$ & $-.014+$ \\
\hline Worker Rep. * sat. & .045 & .015 & -.026 & -.005 & .308 & .093 & -.030 & -.064 \\
\hline _cons & -.792 & \multicolumn{3}{|c|}{ control variables non-reproduced } & \multicolumn{3}{|c|}{ control variables non-reproduced } & roduced \\
\hline Number of obs. & $=$ & 721 & & & Number of obs & $=$ & 613 & \\
\hline Wald chi2(20) & $=$ & 192.47 & & & Wald chi2(20) & $=$ & 128.10 & \\
\hline Prob > chi2 & $=$ & 0.000 & & & Prob >chi2 & $=$ & 0.000 & \\
\hline Log likelihood & $=$ & -547.62 & & & Log likelihood & $=$ & -513.87 & \\
\hline
\end{tabular}

Note 1: B represents the unstandardized coefficients, dy/dx the marginal effects. Note $2: * * *$ Statistically significant at the .001 level;* at the .05 level; + at the .10 .

We constructed the graphs to illustrate this relationship by calculating the probabilities of each choice along the satisfaction scores, while fixing other variables at their mean points. The graph exhibits satisfaction scores on the ordinate and the proportion of agents having made each of the three choices on the axis. The two graphs indicate clearly the "scissor-shaped curve" relationship in both countries, which means that at one point, the two curves are reversed. This observation of reversed double correlation confirms the schema explicitly integrated in the Price model. Most importantly, we clearly notice the different ways in which satisfaction exerts its effects on the attitude -stay or quit- of call center agents: satisfaction reinforces the intent to stay along its full scale range, while its influence on the intent to quit is limited nearly to the negative part of satisfaction, that is the range where agents feel rather dissatisfaction. This is common to both countries. Nonetheless, some differences exist: dissatisfaction (negative part of satisfaction score) appears more directly connected with the increase of intent to quit in France, contrary to Japan where many agents adopt a waiting more ambiguous- attitude. 
Graph: Estimated likelihood of mobility choice by satisfaction scores
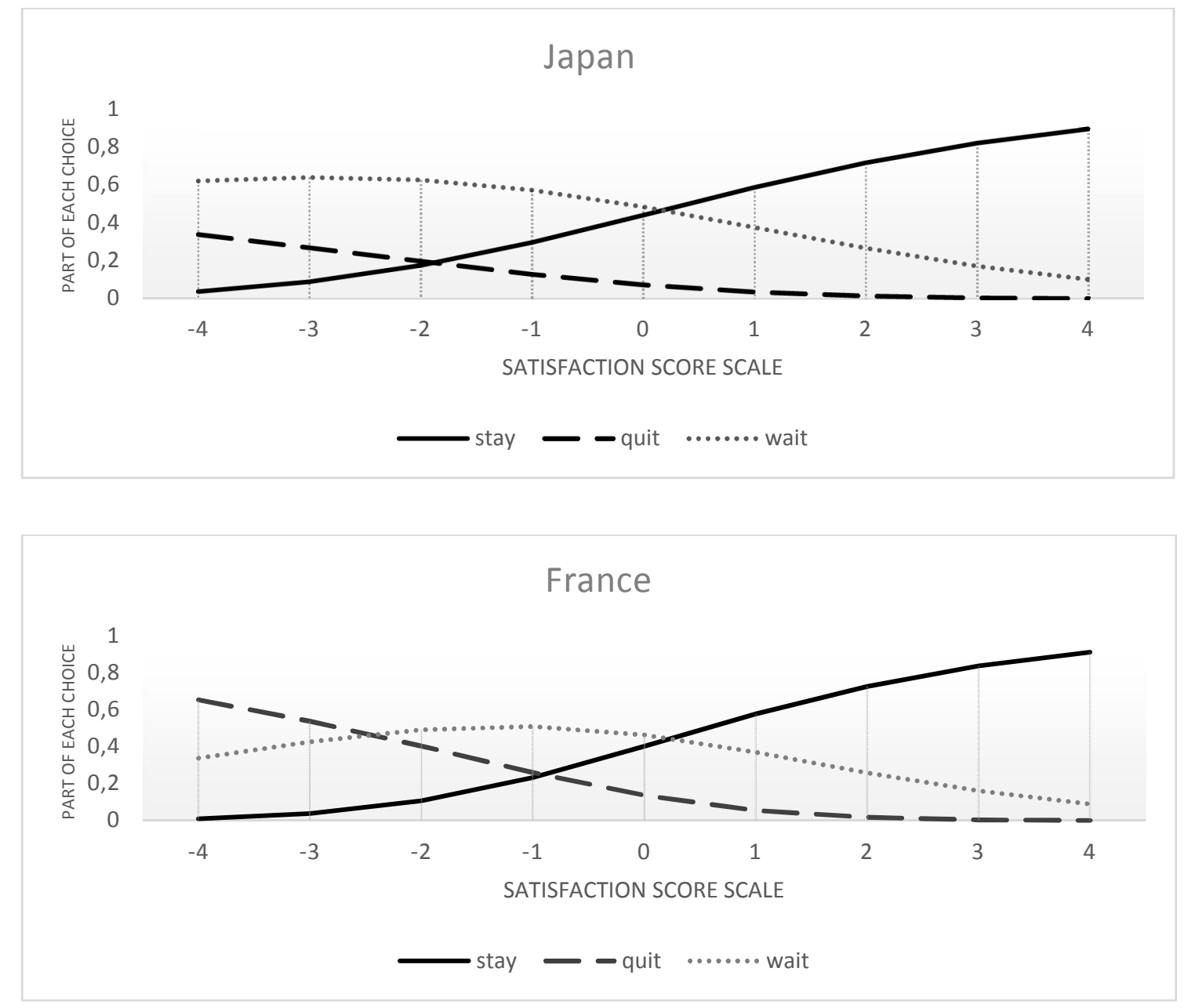

This double correlation may however imply two types of causality: one goes from "good" job satisfaction to stabilization of employees or less willingness to leave; by contrast, the other runs from their stability to a greater satisfaction, moving through the effort to improve their working environments. The latter, backed up by the formulation "Exit or Voice" (Freeman \& Medoff, 1984), would mean that call center agents make efforts to ameliorate their working environments, by voicing their opinions on their working conditions, the pay level or management policies, which can result in bringing a greater satisfaction to employees. Nevertheless, this logic does not seem to be totally at work according to our test, since neither the union membership variable nor the workers' representative system variable, nor the crossing variables (union member*satisfaction, worker rep.* satisfaction) exerts a statistically significant impact on the agents' behavior. This industry faces very competitive market conditions, so that the employees may often choose an "exit strategy". Consequently, the first type of causality is likely to be more plausible, although not yet totally confirmed at this stage of research. 


\section{Conclusion}

Our results support the majority of the predictions made by Price's model (2001), including the correlational relationships of satisfaction between various organizational/managerial practices and the attitudinal expectations (stay-quit) of individuals. Satisfaction in call centers is largely a function of three major factors: autonomy at work, stress and pay level. These fundamental facts, common to France and Japan, are consistent with the conclusions of much past research. Call center activities, standardized by the same technologies and similar operation procedures, partly impose the same burdens on the management wherever they are implemented: time constraint, mental fatigue, pressure on labor costs, etc. These pressures produce in turn the same type of attitudinal reactions from front-line agents in both countries. Globally, the basic logics of Price's model are confirmed.

However, there are many differences in human resource management strategies as well as in the cognitive and psychological perceptions of the call center agents hidden behind this universal trend. The international comparative study allowed us to show simultaneously the fundamental logics of human reactions vis-à-vis basic stimuli, and an array of human perceptions/attitudes necessarily conditioned by the societal or contextual factors of each society.

Satisfaction depends partially on the real pay level, but also on the different ways in which wages are distributed and perceived, according to the socio-organizational position of each individual, both in France and in Japan. The distributive justice incorporated in the employment contract is by nature heavily "context-dependent". Moreover, such exchange is not only organized between the employer and the employee within a particular organization, but also embedded in a societal space that transcends it. In other words, it also depends on the societal context which gives social meanings to it. The other remarkable differences existing between the two countries are linked to sociodemographic factors. Even with similar characteristics, call center agents have different expectations as to the employment or wage conditions, and ultimately their future career plans. These attitudinal reactions are a consequence of HRM strategy in each country, but are, more fundamentally, conditioned by a societal logic which produces social groups in an original way. In this regard, the family structure and the gender division of work are of prime importance in generating such differences, as this sector is dominated by the female population (Dupray \& Nohara, 2013). Thus, they are at the same time the products of and the "resources" used by the call centers' business strategy. Call centers try to build productive efficiency, by offering them different types of psychological contracts. 
If we were to suggest elements to improve the efficacy models of call centers, we would note that the French call centers could enhance the pay ladders or other apparatus to give more long-lasting incentives to their agents, while the Japanese call centers may need to improve the working conditions of the "core workforce" with permanent status, who often serve as a buffer to all types of demand fluctuations and incidents, which results in overwork, stress and fatigue.

Our study has several limits. First, focused only on internal conditions of the organization, our analysis does not take into account the external conditions. In the case of this feminized activity, the intent to quit or to stay may be conditioned by family situations. It will thus be necessary to include these items within the model. Second, by considering the two levels of analysis -individual and societal- we neglected the establishment level (the organization); we need to take into account the internal characteristics of each organization (social climate, business orientation, etc.) with the multilevel analysis model. Third, with our one-shot data, we cannot examine the whole process of turnover model. The collection of longitudinal data will be indispensable for further research developments.

\section{Bibliography}

Akerlof G. (1982) Labor contracts as partial gift exchange, Quarterly Journal of Economics, XCII, 543-569.

Batt R. Nohara H, Kwon H. (2010) Employer Strategies and Wages in New Service Activities: A Comparison of Coordinated and Liberal Market Economies, British Journal of Industrial Relations, 48(2), 400-435

Becker H. S. (1960) Notes on the concept of commitment, American Journal of Sociology, 66, 32-42

Clergeau C. (2004) La gestion des ressources humaines dans les centres d'appels internalisés: le cas des front offices purs, Revue de Gestion des Ressources Humaines, 52, 2-17.

Clugston M. (2000) The mediating effects of multidimensional commitment on job satisfaction and intent to leave, Journal of Organizational Behavior, 21(4), 477-486.

Deci E. L. \& Ryan R. M. (1985) Intrinsic Motivation and Self-Determination in Human Behavior, New York: Plenum Press.

Dupray A. \& Nohara H. (2013) Les conditions d'activité des femmes en couple : une comparaison entre la France et le Japon sur la période 1992-2007, Revue Française de Socio-économie, 12, 149-170.

Freeman R. B. \& Medoff, J. L. (1984) What Do Unions Do?, New York: Basic Books.

Frenkel S. J., Tam M., Korczynski, M., Shire K. (1998) Beyond Bureaucracy? Work Organisation in Call Centres, International Journal of Human Resource Management, 9, 957-979. 
Griffeth R.W., Hom P. W., Gaertner S. (2000) A meta-analysis of antecedents and correlates of employee turnover: update, moderator tests and research implications for the next millennium, Journal of Management, 26, 463-488.

Hellman C. M. (1997) Job satisfaction and intent to leave, Journal of Social Psychology, 137: 677689.

Holman D., Batt, R., Holtgrewe U. (2007) The Global Call Center Report: International Perspectives on Management and Employment, ILR school, Cornell University, 52pages.

Hom P. \& Griffeth, R. (1995) Employee Turnover. Cincinnati, OH: Southwestern.

Hirschman A. (1970) Exit, Voice, Loyalty, Cambridge, MA: Harvard University Press.

Igalens J. (1999) Satisfaction au travail. In Le Duff R. (ed.) Encyclopédie de la Gestion et du Management, Paris: Dalloz, 1246-1247.

Karasek R. \& Theorell, T. (1990) Healthy Work: Stress, Productivity, and the Reconstruction of Working Life, New York: Basic Books.

Lazarus R. S. \& Folkman S. (1984). Stress, Appraisal and Coping. New York: Springer.

Locke E. A. (1976) The nature and causes of job satisfaction. In Dunette M.D. (ed.) Handbook of Industrial and Organization Psychology, Chicago: Rand-McNally, 1297-1349.

Lambert E. G., Hogan N. L. \& Barton S. M. (2001) The impact of job satisfaction on turnover intent: A test of a structural measurement model using a national sample of workers, The Social Science Journal, 38, 233-250.

Lum L., Kervin J., Clark K., Reid, F., Sirola W. (1998) Explaining nursing turnover intent: job satisfaction, pay satisfaction, or organizational commitment, Journal of Organizational Behavior, vol.19, 305-320.

Mathieu J. E. \& Zajac D. M. (1990) A review and meta-analysis of the antecedents, correlates, and consequences of organizational commitment, Psychological Bulletin, 108(2), 171-194.

Maurice M., Sellier F., Silvestre J.-J. (1986) The Social Foundations of Industrial Power: A Comparison of France and Germany, The MIT Press.

Meyer J. P. \& Allen N. J. (1991) A three-component conceptualization of organizational commitment: Some methodological considerations, Human Resource Management Review, 1, 61-98.

Mignonac K. (2004) Que mesure-t-on réellement lorsque l'on invoque le concept de satisfaction au travail?, Revue de Gestion des Ressources Humaines, 53, 80-93.

Mobley W. H. (1977) Intermediate linkages in the relationship between job satisfaction and employee turnover, Journal of Applied Psychology, 62, 237-240.

Mueller C. W. \& Price J. L. (1990) Economic, psychological, and sociological determinants of voluntary turnover. The Journal of Behavioral Economics, 19, 321-335. 
Mueller C. W., Wallace, J. E., Price, J. L. (1992) Employee commitment: Resolving some issues. Work and Occupations, 19, 211-236

Neveu J.-P. (1996) La démission du cadre d'entreprise - Etude sur l'intention de départ volontaire, Paris: Economica.

Nohara H. (1999) L'analyse sociétale des rapports entre les activités féminine et masculine; Comparaison France-Japon, Revue Française de Sociologie, XL-3, 531-558.

Nohara H. \& Tchobanian R. (2014) Le stresse dans le travail du centre d'appels téléphoniques : comparaison France-Japon, In Loïc Lerouge (ed.), Approche interdisciplinaire des risques psychosociaux au travail, Octarès, Toulouse.

Price J. L. (1989) The Impact of Turnover on the Organization. Work and Occupations, 16(4), 461473

Price J. L. (2001) Reflections on the determinants of voluntary turnover. International Journal of Manpower, 22(7), 660-624.

Price J. L. \& Mueller C. W. (1981) A causal model of turnover for nurses, Academy of Management Journal, 24, 543-565.

Rousseau D. M. (1995) Psychological Contracts in Organizations: Understanding Written and Unwritten Agreements. Newbury Park, CA: Sage.

Roussel P. (1996) Rémunération, motivation et satisfaction au travail, Paris, Economica

Russel B. (2008) Call centres: A decade of research, International Journal of Management Reviews, $10,3,195-219$.

Spector P. E. (1997) Job satisfaction: Applications, Assessment, Causes and Consequences. Thousand Oaks, CA: Sage.

Steel R. P. \& Ovalle N. K. (1984) A review and meta-analysis of research on the relationship between behavioral intentions and employee turnover. Journal of Applied Psychology, 69, 673-686.

Taylor P. \& Bain P. (1999) An assembly line in the head': work and employee relations in the call centre, Industrial Relations Journal, 30 (2),101-117.

Tett R. P. \& Meyer J.P. (1993) Job satisfaction, organizational commitment, turnover intention, and turnover: Path analyses based on meta-analytic findings, Personnel Psychology, 46, 259-293

Zapf D. (2002) Emotion work and psychological well-being: a review of the literature and some considerations, Human Resource Management Review, 12, 237-268.

Zimmerman R. D. \& Darnold T. C. (2009) The impact of job performance on employee turnover intentions and the voluntary turnover process: a meta-analysis and path model. Personnel Review, 38, 142-158.

Weiss H. M., Nicholas J. P., Daus, C. (1999) An examination of the joint effects of affective experiences and job beliefs on job satisfaction and variations in affective experiences over time. Organizational Behavior and Human Decision Processes, 78, 1-24. 
Weiss H.M. (2002) Deconstructing job satisfaction: Separating evaluations, beliefs, and affective experiences, Human Resource Management Review, 12, 1-22 
Annex A: Construction of satisfaction score based on the four facets of satisfaction:

a) How satisfied are you with the task content?

b) How satisfied are you with your pay?

c) How satisfied are you with the human relations at your workplace?

d) How satisfied are you overall with your job?

Everyone was asked to answer to these questions ticking a box ranging from 1 to 4 (Likert scale): 1) very satisfied 2) satisfied 3 ) somewhat dissatisfied 4) totally dissatisfied

We used the method of principal components analysis and retained the first of four proposed components, which explains $63 \%$ of the total variance in France and $68 \%$ in Japan.

Annex B: Construction of stress score based on five items of GHQ-12:

a) Do you feel depressed?

b) Are you ever bullied or harassed by customers on the phone?

c) Do you feel tired?

d) Do you feel any physical pain?

e) Do you have trouble sleeping?

Respondents are asked to answer to these questions ticking a box ranging from 1 to 4 (Likert $\begin{array}{llll}\text { scale): 1) very often } & \text { 2) often } & \text { 3) sometimes } & \text { 4) not at all }\end{array}$

From the GHQ-12 (general health questionnaire) developed by MAPI Research Trust (UK), we picked up five items and modified them to fit the $\mathrm{CC}$ sector, as shown above. Based on the method of principal components analysis, we chose the first of four components, which explains $56 \%$ of the total variance in Japan and 57\% in France. 